УДК 339.13

DOI 10.18413/2687-0932-2020-47-2-317-327

\title{
ИССЛЕДОВАНИЕ ПОТРЕБИТЕЛЕЙ КЛИНИНГОВЫХ УСЛУГ В СЕГМЕНТЕ В2С
}

\section{RESEARCH THE CONSUMERS OF CLEANING SERVICES IN B2C SEGMENT}

\author{
Е.В. Смирнова, А.В. Биндюкова \\ E.V. Smirnova, A.V. Bindukova \\ ФГАОУ ВО Сибирский Федеральный Университет, Институт управления бизнес-процессами \\ и экономики, Россия, 660074, г. Красноярск, ул. Киренского, 26а
}

Siberian Federal University School of Business Management and Economics 26A Kirensky st, Krasnoyarsk, 660074, Russia

E-mail: Sev9@list.ru

\begin{abstract}
Аннотация
Статья отражает некоторые результаты проведенного маркетингового исследования рынка клининга в сегменте В2С, представляющие интерес как для понимания состояния и тенденций развития рынка домашнего клининга, так и с методологической точки зрения. Дана оценка состояния рынка «домашнего клининга»: потребность в различного вида клининговых услугах, объем спроса, отношение потенциальных потребителей к цене. Представлены результаты сегментного анализа потребителей. Используемые в работе методы факторного и кластерного анализа позволили достаточно эффективно осуществить сегментацию исследуемого рынка и достаточно полно и объективно описать полученные сегменты на основе изучения поведения потребителей, их мотивации, ценностей и образа жизни.
\end{abstract}

\begin{abstract}
The article highlights the results of a field study of the cleaning services market in the B2C segment for the Krasnoyarsk city. The article assesses the state of the «home cleaning» market, namely the need for various types of cleaning services, the volume of demand, and the ratio of potential consumers to price. The results may be useful for the formation of price policy, because on the basis of constructed demand curves can calculate the elasticity of demand and to make a sales forecast. The article is of interest both for understanding the status and development trends of the home cleaning market, and from a methodological point of view. A psychographic analysis of consumers performed using the factorial, cluster method made it possible to segment the market under study based on the study of consumer behavior, their motivation, values and lifestyle, and to describe the segments obtained and determine the target market. Understanding the status and trends of the market development, the specifics of the target audience will allow formulating the basic approaches to market development and the development of marketing strategy.
\end{abstract}

Ключевые слова: клининговые услуги, сегментация, сегментация по психологическому признаку, рынок «домашнего клининга».

Keywords: cleaning services, segmentation, psychological segmentation, the market of "home cleaning".

\section{Введение}

Для формирования эффективной маркетинговой политики любой компании, особенно в момент становления рынка, как никогда важно понимание состояния и тенденции развития рынка. Прежде всего, важно все, что касается потребительского рынка: объем спроса, отношение к цене, мотивация и особенности потребительского поведения. Особую актуальность приобретает знание размера и структуры потенциального рынка. В данном случае речь идет о сегментации рынка. Целью сегментации является выделение одной или нескольких целевых групп потребителей, под которых «затачивается» весь комплекс маркетинговых мероприятий - от разработки продуктов и сбыта до выбора содержания 
рекламного обращения и медиаканалов. «Сегментирование позволяет выявить различные потребности клиентов, сгруппировать их по степени сходства и адаптировать маркетинговую деятельность к предъявляемым требованиям» [3].

Сегментация, выбор целевых сегментов, позиционирование - основа маркетингового планирования. Определение привлекательности потребительских сегментов рынка и приоритетов в их освоении является одним из важнейших моментов при разработке маркетинг-плана, для чего в свою очередь необходима информация об их величине и характеристиках. Возникает вопрос: как определить основные сегменты и измерить их?

Разбивать рынок на сегменты можно разными способами. Можно использовать и метод «на глазок». «В отечественной и зарубежной практике существуют различные подходы и методы проведения сегментного анализа. Выбор методики сегментирования рынка представляет сложную задачу, решение которой нужно начинать с определения технологии и методов построения сегментов» [3].

Мы рассмотрим кластерный анализ. Объясним почему. Как известно, в качестве классических критериев сегментации рынка выступает социально-экономические и демографические признаки. Однако, как показывает опыт, люди одного и того же социального статуса, уровня дохода, и пр. могут приобретать разные товары и услуги и демонстрировать разное покупательское поведение.

Поэтому сегодня наряду с группировкой потребителей по социально-экономическим, демографическим, географическим характеристикам все большее значение и распространение приобретает так называемая эмпирическая типология потребителя на основе психографического анализа, т. е. сегментация по психологическим признакам, включая сегментацию по поведенческому признаку и сегментацию на основе образа жизни. Для получения необходимой информации, позволяющей составить портрет потенциального потребителя, в анкету для характеристики целевой аудитории был включен большой перечень вопросов относительно мотивации, критериев выбора и других особенностей потребительского поведения, а также системы ценностей и образа жизни. «Таким способом может быть достигнуто достаточно глубокое понимание людей, составляющих каждый сегмент, и, на практике используя это понимание можно «достучаться» до этих людей, заговорить с ними на их языке и представить товар в наилучшем виде» [1].

В то же время изучение потребительского рынка методами психографического анализа вызывает затруднение именно с точки зрения количественного измерения сегментов рынка. Инструментом, позволяющим решить эту задачу, является факторный и кластерный анализ.

Для получения полноценной и достоверной информации о состоянии Красноярского рынка клининговых услуг в сегменте В2С было проведено полноценное полевое маркетинговое исследование.

\section{Методология исследования}

Цель исследования: получение информации о величине и характере спроса на услуги клининга в г. Красноярске в сегменте В2С, а также о характеристиках целевой аудитории услуги «домашнего» клининга, особенностях их покупательского и потребительского поведения.

Задачи исследования:

- определить потенциальную емкость местного рынка клининга в сегменте В2С;

- выявить потенциальный спрос на услуги клининга со стороны домохозяйств г. Красноярска;

- изучить потребителей данной услуги;

- изучить особенности потребительского поведения;

- выявить отношение домохозяйств к клининговым услугам;

- изучить особенности покупательского поведения целевой аудитории;

- произвести сегментацию потребителей услуг «домашнего» клининга;

- определить профиль целевой аудитории. 
Целевые группы исследования: женщины, мужчины, в возрасте от 21 года, имеющие среднедушевой доход не менее 12 тыс. руб., проживающие в благоустроенных квартирах.

География исследования: г. Красноярск. Время опроса - 2014 г.

Методы исследования:

1. Метод сбора первичной информации - личное стандартизированное интервью. Опрос был произведен по разработанной нами анкете Восточно-Сибирским Региональным Агентством Маркетинговых и Социологических Исследований.

Отбор семей для опроса проводился маршрутным методом. В семье опрашивался человек, распоряжающийся домашними финансами и принимающий решения по вопросам организации семейного быта.

2. Методы обработки и анализа информации. Заполненные анкеты были обработаны в программе обработки статистических данных SPSS [11].

3. Сегментация потребительского рынка «домашнего» клининга была осуществлена методами факторного и кластерного анализа.

Факторный метод сегментационного анализа предполагает определение внешнего фактора и так называемых активных переменных, по которым непосредственно происходит формирование сегментов и пассивных переменных, т. е. тех признаков, которые служат для более полного описания уже очерченных сегментов [6].

Кластерный анализ - один из «базовых» методов, используемый в мировой практике многомерной классификации. Кластерный анализ представляет собой класс методов, используемых для классификации объектов или событий в относительно однородные группы, которые называют кластерами (clusters). Объекты в каждом кластере должны быть похожи между собой и отличаться от объектов в других кластерах. В зависимости от высказанного отношения к определенной группе переменных, респондентов относят к соответствующему сегменту [2]. Кластерный анализ как эффективный способ классификации объектов по их признакам хорошо зарекомендовал себя и в маркетинговой деятельности, в частности при сегментации рынка. Алгоритм проведения кластерного анализа содержит такие этапы, как: отбор выборки, определение множества критериев, по которым проводится кластеризация, определения расстояния и степени сходства, к которой причисляют коэффициент корреляции. Важной особенностью методов кластеризации является то, что группы, или кластеры, определяются в процессе анализа, а не заранее, и у исследователя может и не быть априорной информации [5].

Расчет выборки:

$$
n=\frac{1,96^{2} * 0,5 *(1-0,5)}{0,038^{2}}=660,
$$

где $\mathrm{n}$ - объем выборки;

1,96 - коэффициент доверия или нормированное отклонение, определяемое исходя из уровня доверительности $(95 \%)$;

s2 - дисперсия для доли признака равна s2=p*(1-p), где $\mathrm{p}$ - доля признака, дисперсия максимальна при $\mathrm{p}=0,5$;

0,038 - статистическая ошибка выборки $(3,8 \%)$.

Таким образом, для обеспечения репрезентативности выборки необходимо опросить 660 человек и при этом уровень доверительности составит 95 \%, а статистическая ошибка - 3,8 \%.

\section{Результаты исследования}

В данной статье представлены некоторые результаты проведенного ранее исследования, предоставляющие, на наш взгляд, не только фактологический, но и методологический интерес.

Изучение спроса и выявление потребности в услугах «домашнего» клинига.

На момент опроса 59 \% опрошенных оказались незаинтересованы в клининговых услугах.

В качестве причин отсутствия интереса к клининговым услугам - главная (86\% ответов) - отсутствие потребности в услуге: люди отвечали: «справляемся самостоятельно, 
либо «люблю убираться», либо «нет нужды». Только 16 \% ответов - «дорого» и еще 7 \% - «не доверяю чужим».

Наибольший интерес проявлен к следующим видам клининговых услуг: мытье окон, балконов и лоджий (указали $15 \%$ респондентов), чистка ковров (12\%), чистка мебели (6\%), генеральная уборка (4\%). Уборка после ремонта интересует 2,6 \% опрошенных, санитарная уборка после чрезвычайной ситуации - $2 \%$, уничтожение микроклещей в матрасах и коврах $-1,8 \%$.

При этом жители готовы перепоручить профессиональным уборщикам те виды работ, которые вызывают наибольшие трудности при уборке. В то же время опросом выявлена определенная заинтересованность жителей в уборке после ремонта и биоуборке.

38 \% из всех опрошенных проявили заинтересованность в привлечении клининговой компании к уборке подъездов и придомовой территории. Больше всего жильцы заинтересованы в уборке подъездов, вывозе мусора, интересует жильцов также и уборка в лифтах (рис. 1).

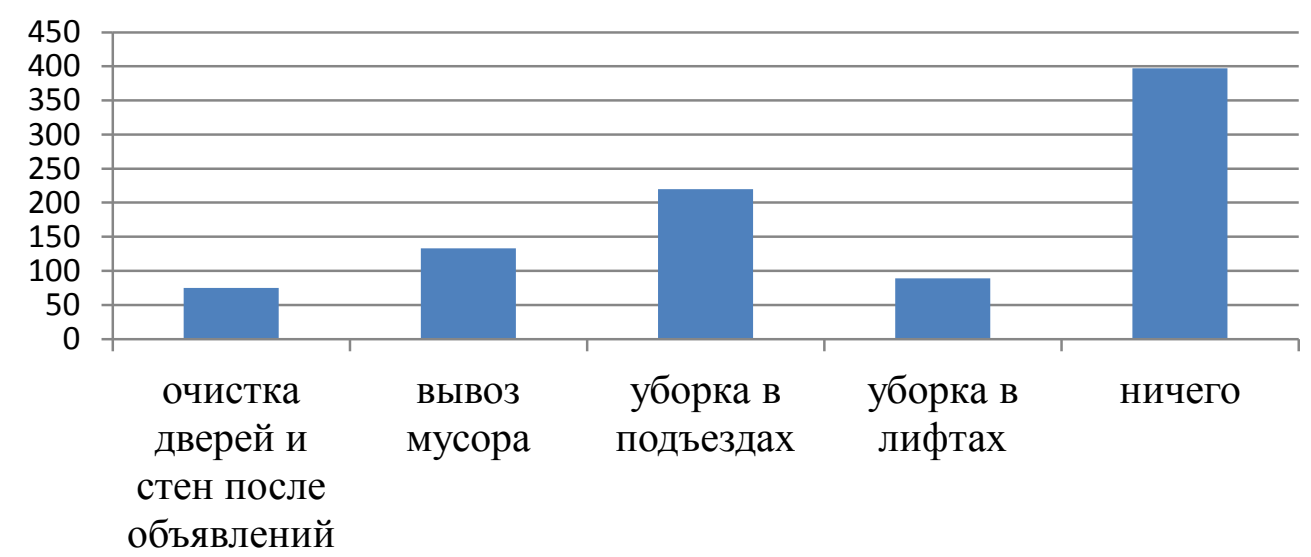

Рис. 1. Виды услуг по уборке подъездов и придомовой территории

Fig. 1. Types of services for cleaning the entrances and the local area

Потенциальная емкость рынка «домашнего» клининга при стоимости уборки одного квадратного метра 40 руб. была определена следующим образом:

$$
\text { ПЕР=ЧН/ЧС * БЖ * ДК * ПК * ПУ }
$$

Таблица 1

Table 1

Определение емкости рынка

Determination of market capacity

\begin{tabular}{|l|l|c|}
\hline Численность населения г. Красноярска & 1035528 чел & ЧН \\
\hline Средний состав семьи & 2,78 чел & ЧС \\
\hline Доля благоустроенного жилья & 0,75 & БЖ \\
\hline $\begin{array}{l}\text { Доля домохозяйств, заинтересованных } \\
\text { в клининговых услугах }\end{array}$ & 0,41 & ДК \\
\hline Средняя площадь квартиры & 56,7 кв. м & ПК \\
\hline Периодичность уборки & 1,5 раз в год & ПУ \\
\hline Стоимость уборки одного квадратного метра & 40 руб. & ЦУ \\
\hline $\begin{array}{l}\text { Потенциальная емкость рынка домашнего } \\
\text { клининга }\end{array}$ & 389669559 руб. в год & ПЕР \\
\hline
\end{tabular}

При этом надо понимать, что к регулярному привлечению клининговых компаний для выполнения работ по поддержанию чистоты и порядка в доме город пока не готов. Население интересуют главным образом разовые работы, как правило, сезонного характера, связанные с 
мытьем окон и балконов, чисткой ковров. В то же время существует нишевой рынок для биоуборки и уборки после ремонта. образом:

Емкость рынка для услуги «уборка после ремонта» может быть определена следующим

Таблица 2

Table 2

Определение емкости рынка для услуги «уборка после ремонта»

Determination of market capacity for the service «cleaning after repair»

\begin{tabular}{|l|l|c|}
\hline Численность населения г. Красноярска & 1035528 чел & ЧН \\
\hline Средний состав семьи & 2,78 чел & ЧС \\
\hline Доля благоустроенного жилья & 0,75 & БЖ \\
\hline $\begin{array}{l}\text { Доля домохозяйств, заинтересованных } \\
\text { в услуге «уборка после ремонта» }\end{array}$ & 0,026 & ДР \\
\hline Средняя площадь квартиры & 56,7 кв. м & ПК \\
\hline Периодичность уборки после ремонта & 0,2 & ПУ \\
\hline $\begin{array}{l}\text { Стоимость уборки одного квадратного метра } \\
\text { после ремонта }\end{array}$ & 55 руб. & ЦУ \\
\hline Потенциальная емкость рынка & 4530304 руб. в год & ПЕР \\
\hline
\end{tabular}

Для сравнения, общая емкость рынка клининга г. Красноярска по экспертным оценкам специалистов, на тот же период составляет примерно $1 \%$ от общего объема российского рынка клининга, то есть порядка 1,04 млрд руб. [8].

По результатам опроса в программе SPSS были построены кривые спроса на наиболее востребованные услуги (рис. 2, 3, 4, 5).

Данные кривые могут быть использованы для расчета коэффициента эластичности спроса и при формировании ценовой политики. Как видно из графиков, при невысоких ценах (не выгодных производителю) спрос достаточно эластичен и снижение цены может вызвать достаточный рост клиентов и обеспечить увеличение общей выручки. Однако при достаточно адекватных ценах (покрывающих затраты производителя и гарантирующих определенный уровень рентабельности) спрос становится неэластичным. Это значит, что любые манипуляции по снижению цены приведут к сокращению выручки, поскольку не будут компенсированы ростом продаж. Данные обстоятельства в очередной раз подтверждают целесообразность использования при формировании ценовой политики стратегии снятия сливок.

\section{Критерии выбора клининговой компании}

Среди критериев выбора клининговой компании наиболее значимые: доступные цены (назвали $72 \%$ ответивших), профессионализм - $45 \%$, ответственность за качество $43 \%$. Репутация компании важна для $26 \%$ респондентов, опыт работы и надежность - для $22 \%$, использование экологических материалов - для $16,5 \%$.

В то же время оперативность, ассортимент предлагаемых услуг, ответственность за сохранность имущества оказались менее значимыми для респондентов факторами (рис. 6).

\section{Эмпирическая типология потенциальных клиентов услуг «домашнего» клининга на основе психографического анализа}

Исследование красноярского рынка клининга было выполнено методами факторного и кластерного анализа с предварительной оценкой факторов, определяющих потребительское поведение.

Сначала для выявления основных характеристик потенциальных потребителей клининговых услуг, результаты опроса, касающиеся психографических характеристик респондентов, были обработаны методами факторного анализа, с помощью которого была решена задача редуцирования исходного множества факторов и их укрупнения. 


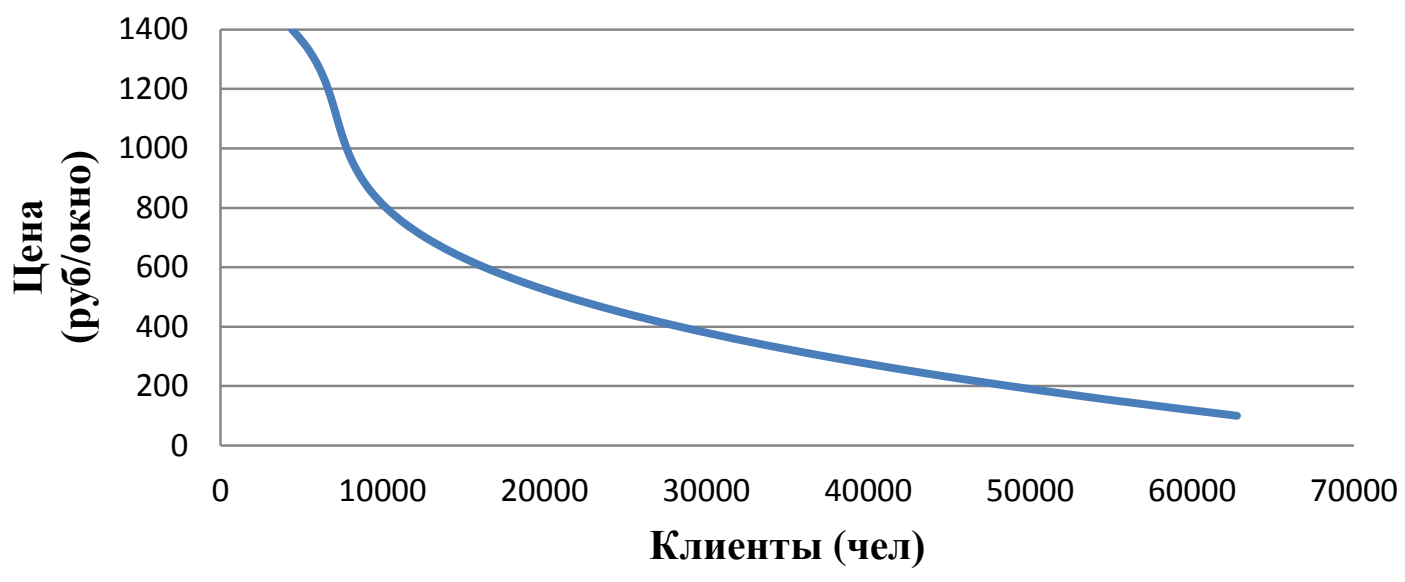

Рис. 2. Кривая спроса на услугу «мытье окон»

Fig. 2. Curve of demand for the «window washing» service

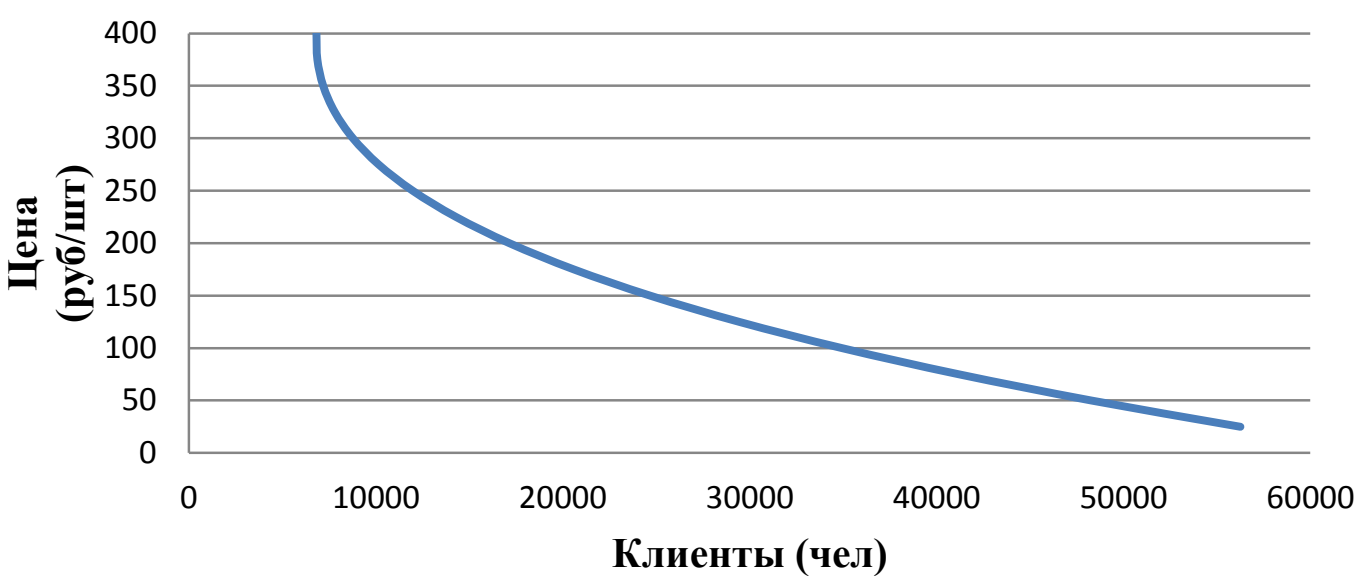

Рис. 3. Кривая спроса на услугу «чистка ковров»

Fig. 3. The demand curve for the service «carpet cleaning»

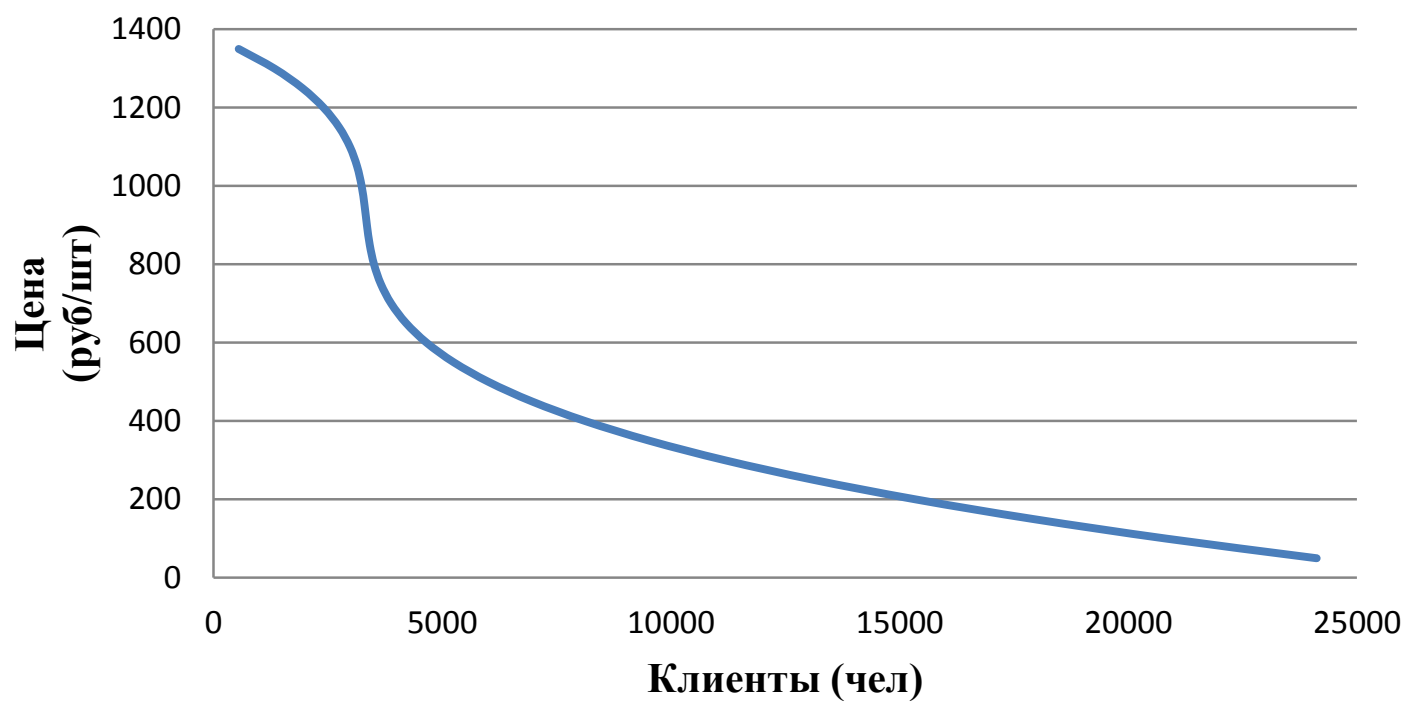

Рис. 4. Кривая спроса на услугу «чистка мебели»

Fig. 4. Demand curve for the «furniture cleaning» service 


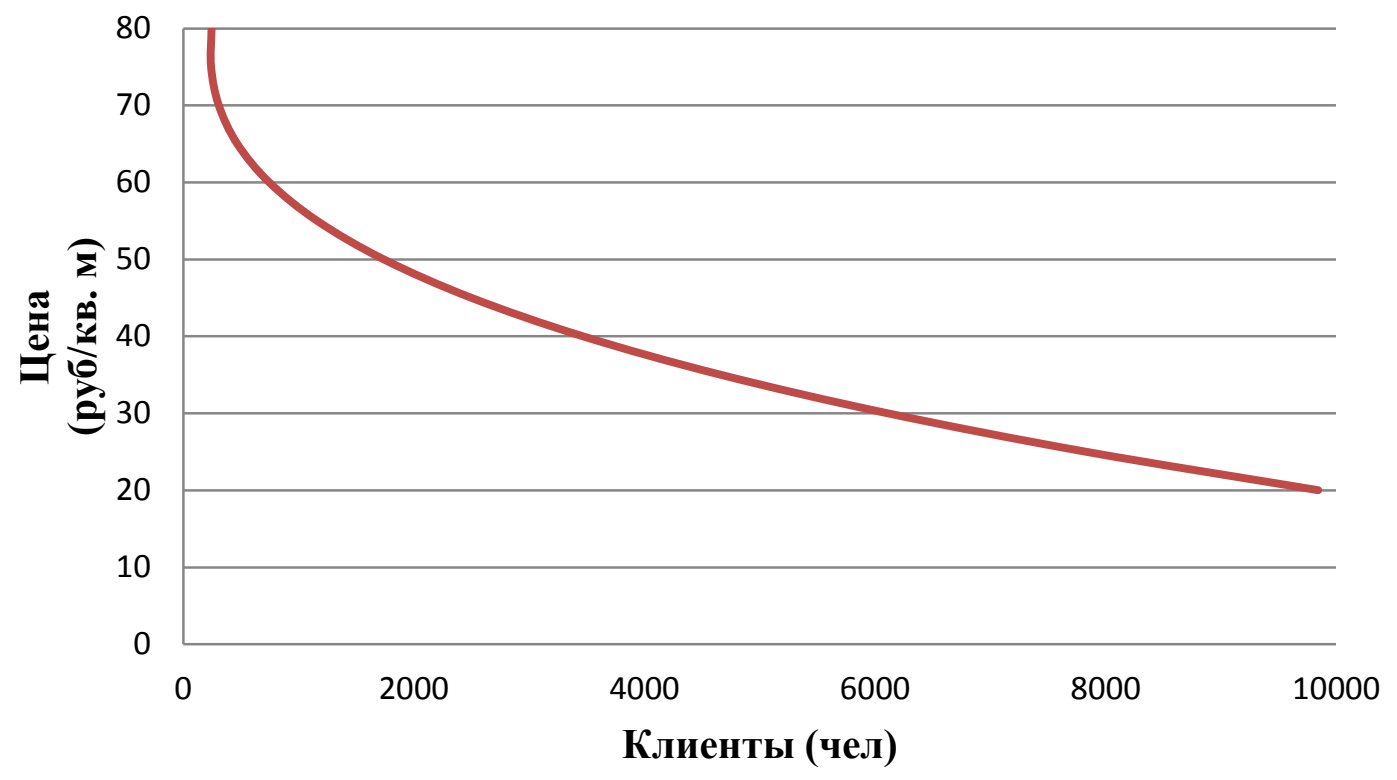

Рис. 5. Кривая спроса на услугу «генеральная уборка»

Fig. 5. The demand curve for the «general cleaning» service

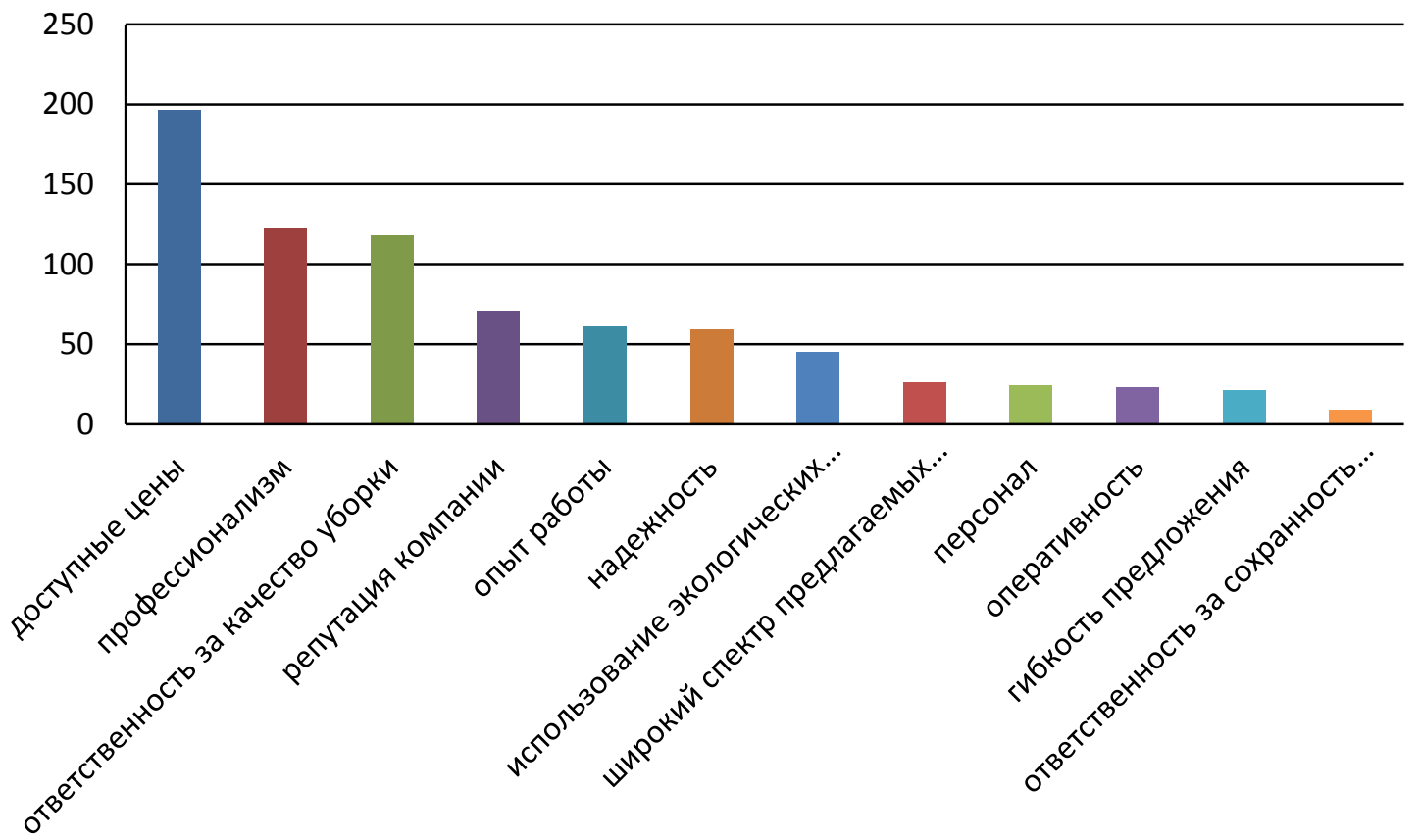

Рис. 6. Критерии выбора клининговой компании

Fig. 6. Criteria for choosing a cleaning company

В результате факторного анализа были получены шесть латентных факторов (признаков сегментации), влияющих на потребительское поведение потенциальных клиентов клининговых услуг:

1. Приверженность бренду;

2. Фанатичное отношение к чистоте;

3. Закрытость / открытость;

4. Доверие профессионалам;

5. Консерватизм / новаторство;

6. Ориентация на авторитеты. 
Для формирования сегментов полученные результаты были обработаны методом кластерного анализа. Как известно, «в бизнесе кластерный анализ применяется для сегментации клиентов, аудиторий, продуктов и рынков. А еще при помощи него выявляют психотипы» [4].

В результате в зависимости от степени влияния каждого из факторов все респонденты были разбиты на 4 кластера. Характеристики и размеры кластеров представлены в таблице 5, 6.

Таблица 3

Table 3

Описание кластеров
Cluster Description

\begin{tabular}{|c|c|c|c|}
\hline Название кластера & Размер & Отличительные характеристики & Общие характеристики \\
\hline $\begin{array}{l}\text { 1.Консерваторы } \\
\text { (традиционалисты) }\end{array}$ & $25 \%$ & $\begin{array}{l}\text { Зависимость от общественного } \\
\text { мнения } \\
\text { Ориентация на традиционный } \\
\text { уклад (традиционный взгляд на } \\
\text { распределение обязанностей в } \\
\text { семье) } \\
\text { Большая открытость }\end{array}$ & \multirow{4}{*}{$\begin{array}{l}\text { Высокозначимыми } \\
\text { факторами являются } \\
\text { забота о жилище и } \\
\text { любовь к уборке } \\
\text { Факторы среднего } \\
\text { уровня значимости: } \\
\text { мобильность и } \\
\text { ориентация на экологию } \\
\text { и здоровый образ жизни }\end{array}$} \\
\hline $\begin{array}{l}\text { 2.Новаторы } \\
\text { (современные) }\end{array}$ & $8,5 \%$ & $\begin{array}{l}\text { Доверяют авторитетному мнению } \\
\text { и профессионалам } \\
\text { Не склонны полагаться на мнение } \\
\text { большинства } \\
\text { Большая чем у других } \\
\text { ориентация на здоровый образ } \\
\text { жизни и экологию } \\
\end{array}$ & \\
\hline $\begin{array}{l}\text { 3.Обычные Середняки } \\
\text { (массовый рынок) }\end{array}$ & $59,5 \%$ & $\begin{array}{l}\text { Нет четко выраженных } \\
\text { приоритетов } \\
\text { Чуть меньшая зацикленность на } \\
\text { доме и уборке, } \\
\text { чуть меньшая ориентация на } \\
\text { экологию и здоровый образ } \\
\text { жизни } \\
\text { чуть выше мобильность } \\
\text { чуть меньше доверие } \\
\text { профессионалам }\end{array}$ & \\
\hline 4. Перфекционисты & $7 \%$ & $\begin{array}{l}\text { Приверженцы бренду, фанаты } \\
\text { чистоты } \\
\text { Закрыты (низкий уровень } \\
\text { гостеприимства, неприятие } \\
\text { чужих в доме) }\end{array}$ & \\
\hline
\end{tabular}
таблице 6.

Социально-демографическая характеристика полученных сегментов представлена в Определение целевого рынка

Совершенно очевидно, что наиболее привлекательным сегментом рынка являются «новаторы» (одинокие состоятельные мужчины и женщины, проживающие в новых достаточно больших квартирах и имеющие в качестве дополнительного «загрязняющего» фактора домашних животных), их доля составляет 8,5\% от потенциального рынка. Потенциальная емкость данного сегмента равна 33,15 млн руб. Данный сегмент, кстати, малочувствителен к цене. Поэтому может быть использована стратегия снятия сливок (установление более высоких цен с последующим понижением для проникновения на массовый рынок). 
Социально-демографические характеристики выявленных сегментов

Socio-demographic characteristics of the identified segments

\begin{tabular}{|c|c|c|c|c|}
\hline \multirow{2}{*}{$\begin{array}{c}\text { Социально- } \\
\text { демографические } \\
\text { характеристики }\end{array}$} & \multicolumn{4}{|c|}{ Сегменты } \\
\hline & Консерваторы & Новаторы & $\begin{array}{c}\text { Обычные } \\
\text { Середняки }\end{array}$ & Перфекционисты \\
\hline Тип жилья & $\begin{array}{l}\text { новостройка, } \\
\text { улучшенная } \\
\text { планировка }\end{array}$ & новостройки & $\begin{array}{l}\text { улучшенная } \\
\text { планировка }\end{array}$ & хрущевка \\
\hline Состояние жилья & $\begin{array}{l}\text { новая либо } \\
\text { требует } \\
\text { косметического } \\
\text { ремонта } \\
\end{array}$ & новая & среднее & $\begin{array}{l}\text { требует } \\
\text { косметического } \\
\text { либо капитального } \\
\text { ремонта }\end{array}$ \\
\hline Площадь квартиры & $\begin{array}{l}\text { средняя либо } \\
\text { большая }\end{array}$ & $\begin{array}{l}\text { средняя, } \\
\text { большая }\end{array}$ & средняя, большая & $\begin{array}{l}\text { маленькая, либо } \\
\text { средняя }\end{array}$ \\
\hline Возраст & до 44 & $25-34$ и $45-54$ & средний & $55+$ \\
\hline Образование & высшее & высшее & $\begin{array}{l}\text { среднее } \\
\text { специальное } \\
\text { высшее }\end{array}$ & $\begin{array}{l}\text { среднее } \\
\text { специальное }\end{array}$ \\
\hline $\begin{array}{l}\text { Семейное } \\
\text { положение }\end{array}$ & $\begin{array}{l}\text { семья с } \\
\text { маленькими } \\
\text { детьми }\end{array}$ & $\begin{array}{l}\text { больше } \\
\text { одиноких, } \\
\text { больше } \\
\text { мужчин }\end{array}$ & $\begin{array}{l}\text { традиционная } \\
\text { семья } 1-2 \text { детей }\end{array}$ & $\begin{array}{l}\text { живущие с кем-то } \\
\text { вдвоем (причем с } \\
\text { мужем - в } \\
\text { половине случаев, } \\
\text { в остальных, } \\
\text { видимо, со взрослым } \\
\text { ребенком) }\end{array}$ \\
\hline Состав семьи & 3-2-4 человека & 1-2-3 человека & 2-3-4 человека & 2 \\
\hline $\begin{array}{l}\text { Наличие маленьких } \\
\text { детей }\end{array}$ & максимальное & среднее & среднее & минимальное \\
\hline Наличие пожилых & минимальное & нет & минимальное & максимальное \\
\hline Наличие животных & среднее & $\begin{array}{l}\text { максимальное, } \\
\text { наибольший } \\
\text { удельный вес } \\
\text { собак (по } \\
\text { сравнению с } \\
\text { другими } \\
\text { группами) } \\
\end{array}$ & $\begin{array}{l}\text { среднее, } \\
\text { преимущественно } \\
\text { кошки }\end{array}$ & минимальное \\
\hline Доход & средний & выше среднего & средний & ниже среднего \\
\hline Род деятельности & $\begin{array}{l}\text { больше } \\
\text { работающих в } \\
\text { бюджетной } \\
\text { сфере, больше } \\
\text { бизнесменов }\end{array}$ & $\begin{array}{l}\text { максимальное } \\
\text { количество } \\
\text { бизнесменов и } \\
\text { работающих в } \\
\text { коммерческой } \\
\text { сфере и на } \\
\text { госслужбе }\end{array}$ & $\begin{array}{l}\text { все виды } \\
\text { деятельности }\end{array}$ & $\begin{array}{l}\text { большой удельный } \\
\text { вес пенсионеров, } \\
\text { максимальное } \\
\text { количество } \\
\text { служащих без } \\
\text { высшего } \\
\text { образования }\end{array}$ \\
\hline
\end{tabular}

Далее по привлекательности следуют сегмент 1 (25\%) и 2 (59,5\%). Для первого сегмента (молодые семьи с маленькими детьми, проживающие также в достаточно новом или в хорошем состоянии жилье) должна быть создана дополнительная мотивация для обращения в клининговую компанию, поскольку это семьи с традиционным представлением о распределении семейных обязанностей, предполагающим, что поддержание чистоты и порядка в доме - обязанность жены. Однако, как известно, «жена не посудомойка», на этом может быть построена рекламная компания. Нетрудно подсчитать, что за 250 часов в год можно, например, освоить курс «маркетинг» и «маркетинговые коммуникации» либо уделить это же время своей семье, мужу, детям и т. д. В то же время, как показал анализ, в семьях, 
имеющих маленьких детей, на уборку тратится на треть времени больше. То есть потребность в уборке выше. Главное, преодолеть стереотипы, что всем этим должна заниматься жена.

Третья группа - массовый рынок может стать более привлекательным по мере освоения рынка и снижения цены на клининговые услуги.

И наконец, 4 сегмент (бабушки-чистюли без высшего образования в маленьких хрущевках, требующих косметического либо капитального ремонта, с низким уровнем дохода, живущие с кем- то вдвоем либо с мужем, либо со взрослым ребенком) не представляет интереса для клининговых компаний, несмотря на приверженность чистоте и порядку по своим социально-демографическим характеристикам.

\section{Заключение}

В ходе исследования был оценен потенциал рынка «домашнего» клининга, осуществлена его сегментация и предложены варианты возможных маркетинговых стратегий освоения данного рынка.

Так, в ходе проведенного полевого исследования было выявлено отсутствие достаточно значимого спроса на услуги клининговых компани со стороны домохозяйств, что обусловлено несформированной потребностью частного сектора (на момент опроса 59 \% опрошенных домохозяйств продемонстрировали незаинтересованность в клининговых услугах), высокими ценами на клининговые услуги, предлагаемыми операторами, а также неразвитостью клинингового рынка в целом (в значительной мере функционирующие на рынке города клининговые компании обслуживают промышленный рынок). Потенциальная емкость рынка «домашнего» клининга при стоимости уборки одного квадратного метра в размере 40 рублей была оценена в 389,7 млн рублей.

К регулярному привлечению клининговых компаний для выполнения работ по поддержанию чистоты и порядка в доме город пока не готов. Население интересуют главным образом разовые работы, как правило, сезонного характера, связанные с мытьем окон и балконов, чисткой ковров. Также существует нишевой рынок для биоуборки и уборки после ремонта.

В то же время более $40 \%$ опрошенных проявили интерес к клининговым услугам, при этом, средняя цена, которую потенциальные потребители клининговых услуг готовы платить за квадратный метр площади жилья, на четверть ниже минимальной рыночной цены, предлагаемой на момент исследования операторами рынка. Т. е. даже те, кто заинтересован в привлечении профессиональных уборщиков, не готовы платить запрашиваемую цену.

В ходе исследования был выявлен ряд обстоятельств, которые в дальнейшем могут быть использованы для актуализации спроса на клининговые услуги. Существующая потенциальная потребность в услуге может быть актуализирована при условии реализации интенсивной политики продвижения для компании, которая решит осваивать рынок клининга в сегменте B2C.

Наиболее значимыми факторами для выбора клининговой компании наряду с доступными ценами оказались: профессионализм и ответственность за качество (45-43\% опрошенных). Репутация компании важна для $26 \%$ респондентов, опыт работы и надежность для $22 \%$, использование экологических материалов - для 16,5\%. Оперативность, ассортимент предлагаемых услуг, ответственность за сохранность имущества - оказались менее значимыми для респондентов факторами. Данная информация позволит клининговым компаниям понять тригерные точки своего развития.

Выполненный факторный и кластерный анализ позволил осуществить сегментацию потенциального рынка, описать выявленные сегменты и определить целевой рынок. Так, были сформированы и описаны с точки зрения психографических и поведенческих характеристик четыре кластера (новаторы, консерваторы, обычные середняки, перфекционисты). Дан их социально-демографический портрет.

Наиболее привлекательным сегментом рынка для первичного освоения оказались «новаторы» (одинокие или малосемейные состоятельные мужчины и женщины, проживающие в новых достаточно больших квартирах и имеющие в качестве дополнительного «загрязняющего» фактора домашних животных). Определена 
потенциальная емкость данного сегмента. Данный сегмент малочувствителен к цене. Поэтому при формировании ценовой политики на клининговые услуги для данного сегмента рынка может быть использована стратегия снятия сливок.

Таким образом, только полноценное знание и понимание потребительского рынка позволяет компании грамотно выбрать стратегию своего развития и эффективно осуществлять маркетинговую политику.

\section{Список литературы}

1. Гантнер Б. 2001. Типы потребителей: введение в психографику / пер. с англ. под ред. И.В. Андреевой. Спб., Питер, 304.

2. Драганчук Л. 2005. Использование кластерного метода в сегментном анализе рынка. Маркетинг в России и за рубежом. № 4 . 23-28.

3. Дибб С. 2002. Практическое руководство по сегментированию рынка. Спб., Питер, 240.

4. Климов А. Кластерный анализ и сегментация. https://tidydata.ru/segmentation.

5 Молодецкая С.Ф. 2012. Кластерный анализ в сегментации рынка. Научно-информационный электронный журнал научных публикаций студентов и молодых ученых «ЭГО». № 3.

6 Напалкова А. 2016. Методика сегментирования рынка на основе факторного и кластерного анализов на примере розничного сектора фармацевтического рынка. Практический маркетинг №5, 38-48.

7. «Новости клининга», Клининговый портал «Уборка», 2013-2019 гг., www.Uborka.su.

8. «Обзор: Клининговые компании», Ли Е.Б., 2008. Деловой квартал г. Красноярск, № 16 (118). j1aasb.xn--p1ai/

9. Сайт союза клининговых компаний России, «Общие сведения», 2013-2019г. http://www.xn--

10.Смирнова Е. 2015. Типология потребителей рыбо- и морепродуктов на основе психографического анализа. Экономика сельскохозяйственных и перерабатывающих предприятий. № 9, 57-61.

11.Таганов Д. 2005. SPSS: статистический анализ в маркетинговых исследованиях. Спб., Питер, 192.

12. Форман Д. 2016. Много цифр: Анализ больших данных при помощи Excel. М.: Альпина Паблишер,. 464.

\section{References}

1. Gantner B. 2001. Types of consumers: an introduction to psychography / trans. with eng. under the editorship of I.V. Andreeva. St. Petersburg, Peter, 304.

2. Draganchuk L. 2005. Using the cluster method in segment analysis of the market. Marketing in Russia and abroad. No. 4. 23-28.

3. Dibb S. 2002. A practical guide to market segmentation. St. Petersburg, Peter, 240.

4. A. Klimov. Cluster analysis and segmentation. https://tidydata.ru/segmentation.

5. Molodetskaya S.F. 2012. Cluster analysis in market segmentation. Scientific and electronic electronic journal of scientific publications of students and young scientists "EGO". Number 3.

6. Napalkova A. 2016. The methodology of market segmentation based on factorial and cluster analysis on the example of the retail sector of the pharmaceutical market. Practical Marketing No. 5, 38-48.

7. «Cleaning News», Cleaning portal «Cleaning», 2013-2019, www.Uborka.su.

8. «Review: Cleaning companies», Lee EB, 2008. Business quarter, Krasnoyarsk, No. 16 (118).

9. The site of the Union of Cleaning Companies of Russia, "General Information", 2013-2019. http: //www.xn--j1aasb.xn--p1ai/.

10. Smirnova E. 2015. Typology of consumers of fish and seafood based on psychographic analysis. Economics of agricultural and processing enterprises. No. 9, 57-61.

11. Taganov D. 2005. SPSS: statistical analysis in marketing research. SPb., Peter, 192.

12. Foreman D. 2016. Many Figures: Big Data Analysis with Excel. M.: Alpina Publisher. 464.

\section{Ссылка для цитирования статьи For citation}

Смирнова Е.В., Биндюкова А.В. 2020. Исследование потребителей клининговых услуг в сегменте B2C. Экономика. Информатика. 47 (2): 317-327. DOI: 10.18413/2687-0932-2020-47-2-317-327.

Smirnova E.V., Bindukova A.V. 2020. Research the consumers of cleaning services in B2C segment. Economics. Information technologies. 47 (2): 317-327 (in Russian). DOI: 10.18413/2687-0932-2020-47-2317-327. 